Research Article

\title{
Comparative study of Oral Nutritional Supplements vs Intralesional Triamcinolone and Hyaluronidase in Oral Submucous Fibrosis
}

\author{
Goswami $\mathbf{R}^{1}$, Gangwani $\mathrm{A}^{2}$, Bhatnagar $\mathrm{S}^{3}$, Singh $\mathrm{D}^{4}$ \\ ${ }^{1}$ Dr Reema Goswami, Assistant Professor, Department of E.N.T , ${ }^{2}$ Dr.Amar Gangwani, Assistant Professor Department of \\ Pathology, ${ }^{3}$ Dr Shweta Bhatnagar, Assistant Professor, Department of Dentistry, ${ }^{4}$ Dr Deepti Singh, Senior Resident, Department \\ of ENT. All are affiliated to Bundelkhand Medical College Sagar, MP, India
}

Address for correspondence: Dr. Reema Goswami, Email: reemadevgoswami@gmail.com

\begin{abstract}
Introduction: Oral submucous fibrosis (OSMF) is a common premalignant condition found in Indian subcontinent caused by chewing arecanut, betel quid and gutkha with tobacco. A standard treatment to manage this condition is not yet available. The various modalities of treatment are nutritional oral antioxidants, intralesional injections, and surgical removal of bands. We compared the efficacy of intraoral administration of vitamin B combined with lycopene with intralesional triamcinolone acetonide combined with hyaluronidase and oral vitamin B complex with lycopene. Methods: 80 patients suffering from OSMF diagnosed clinically were treated in Bundlekhand Medical College Sagar for 4 months. The patients were divided into two groups randomly. Group A patients received oral administration of vitamin B complex, lycopene and topical triamcinolone for 4 months. Group B received weekly intralesional injections of triamcinolone combined with hyaluronidase for 8 weeks along with vitamin $\mathrm{B}$ complex, lycopene and topical triamcinolone for 4 months. Treatment outcome was evaluated on the basis of improvement in mouth opening, decrease in burning sensation and healing of ulceration. Result: Group B patients receiving intralesional injections of triamcinolone and hyaluronidase along with nutritional supplements showed improvement in degree of trismus as well as burning sensation and ulceration as compared to Group A receiving only nutritional supplements. Conclusion: Intralesional injection of triamcinolone combined with hyaluronidase with oral antioxidants is more effective in treating the patients with OSMF than antioxidants alone. No side effects were seen in both the groups though some patients complained of pain during administration of injection.
\end{abstract}

Key words: Oral submucous fibrosis, Triamcinolone acetonide, Hyaluronidase, Lycopene, Premalignant condition, Interincisal distance.

\section{Introduction}

Oral submucous fibrosis (OSMF) is a chronic, complex, irreversible, highly potent precancerous condition characterised by juxta-epithelial inflammatory reaction and progressive fibrosis of the submucosal tissue i.e. lamina propria and deeper connective tissue [1]. The incidence of OSMF is higher in people from certain parts of the world including South East Asia, South Africa and Middle East. Recent epidemiological data indicates that the number of cases of OSF has rapidly increased in India from an estimated 250,000 cases in 1980 to 2 million cases in 1993 $[2,3]$.

Chronic exposure of betelnut and prolonged deficiency of iron and zinc may lead to an alteration in oral mucosa which

Manuscript received: $16^{\text {th }} \mathrm{Feb} 2014$

Reviewed: $25^{\text {th }}$ Feb 2014

Author Corrected: $13^{\text {th }}$ Mar 2014

Accepted for Publication: $19^{\text {th }}$ Mar 2014 causes hypersensitivity leading to formation of collagen fibers in lamina propria [1-3]. In initial phase of disease, mucosa feels leathery with palpable fibrotic bands. In advanced stage the oral mucosa loses its resiliency and becomes blanched and stiff. Other features of disease include xerostomia, recurrent ulceration and pigmentation of oral mucosa, dryness of mouth, burning sensation, decreased mouth opening and tongue protrusion [1].

Histopathological examination shows subepithelial fibrosis and chronic inflammation accompanied by hyalinization and loss of vascularity, squamous hyperplasia with parakeratosis [1]. Treatment of patients with oral submucous fibrosis depends on the degree of clinical involvement. 
The aim of the present study was to compare the results of treatment with intralesional steroids combined with hyaluronidase with vitamin $\mathrm{B}$ and lycopene vs oral administration vitamin B complex and lycopene only.

\section{Material and Methods}

80 patients suffering from oral submucous fibrosis diagnosed clinically were treated at Bundelkhand Medical College Sagar for a period of 4 months and followed up for another 2 months. The criteria for the diagnosis of OSMF were based on fibrotic bands over oral mucosa, opaque mucosa and decreased mouth opening. The distance between the incisor edges of upper and lower central incisor was measured using geometric compass and scale.

Occupational history and personal history with special preference to betel nut chewing, smoking, drinking alcohol was taken. Routine blood test, blood sugar, urine examination and HIV test was done to detect any systemic disease and immunocompromised conditions.

Patients suffering systemic diseases, diabetes, immunocompromised conditions were excluded from the study. Patients suffering from temporomandibular joint problems and prior history of mandibular fracture were also excluded. All patients were advised to stop the habit of tobacco chewing at the start of the treatment.

The patients were divided randomly into two groups based on administration of medical treatment only and medical treatment combined with intralesional injections. Group A patients were administered with vitamin B complex tablet orally in a dose of $200 \mathrm{mg}$ once daily, lycopene tablet and topical triamcinolone to be applied over mucosal ulcer at bed time. The duration of treatment was for 4 months.

Group B patients were given weekly submucosal injection of $1 \mathrm{ml}$ triamcinolone $(40 \mathrm{mg} / \mathrm{ml})$ combined with injection hyaluronidase 1500IU diluted in $1 \mathrm{ml}$ distilled water administered with a 26 gauze needle, $0.2 \mathrm{ml}$ per site. The intralesional injections were given for 8 weeks. The treatment regime for Group B also included oral Vitamin B complex $200 \mathrm{mg}$ once daily and lycopene tablet. The total duration of treatment was for 4 months.

The patients were followed for 2 months after treatment. All patients were evaluated every week by measuring inter incisal distance and then after completion of treatment. i.e. 4 months and then after 2 months of follow up.

\section{Results}

The clinical study consisted of 80 patients attending ENTand Dental OPD in Bundelkhand medical college Sagar during a period of one year (Dec 2012 to Dec 2013).

Age: The maximum number of patients i e 41.25\% (33 patients) belonged to the age group of 21-25 years followed by $16.25 \%$ patients in the age group of 26-30 years.

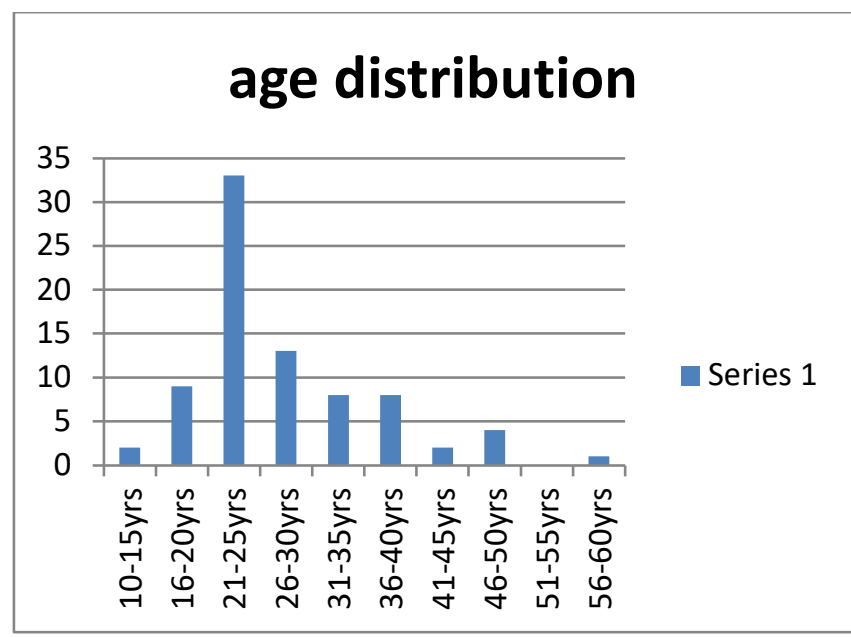

Fig 1: Age distribution of Patients

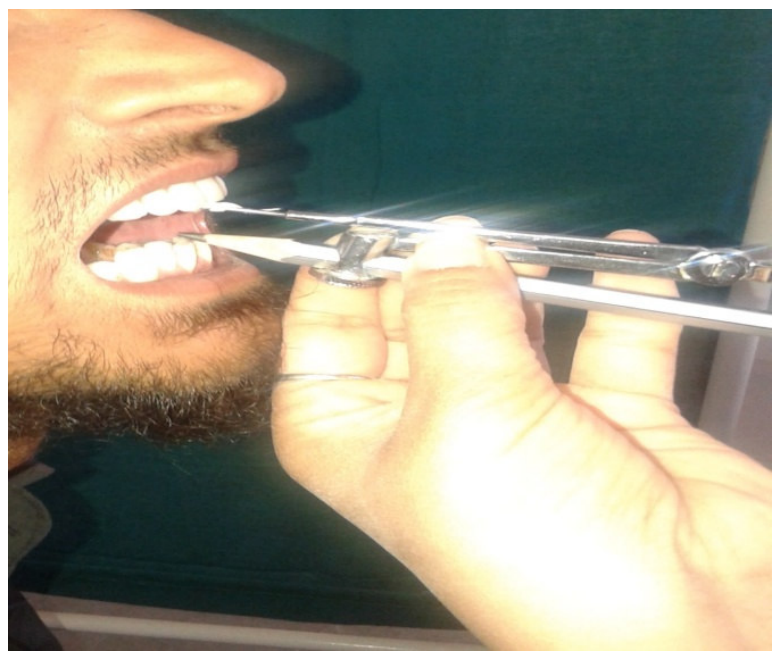

Fig 2: Measuring inter incisal distance with a geometric compass

Sex distribution: There were 65 males and 15 females out of 80 patients studied and the male to female ratio was $4.3: 1$

Addiction: All the patients in the study presented with a history of gutkha chewing. Approximately $19 \%$ of patients presented with history of tobacco chewing for 4 to 6 years. 


\section{Result of medical management}

After 4 months of treatment with vitamin B complex, lycopene and topical application of triamcinolone in group A, 62\% patients were relieved of burning sensation and $70 \%$ patients were relieved of ulceration. There was 1 to $5 \mathrm{~mm}$ increase in interincisal distance in 5 patients only out of 40 patients.

$80 \%$ of Group B patients who were given intralesional injections of triamcinolone + hyaluronidase along with oral medication felt a subjective sense of relaxation in stiffness in mouth after 8 injections, however only $62 \%$ of patients showed actual increase in inter incisal distance. $92 \%$ patients showed improvement in burning sensation and $80 \%$ showed decrease in ulceration.

On applying the unpaired t test for increase in inter incisal distance the two tailed $\mathrm{P}$ value is $<0.0001$. By conventional criteria this difference is considered to be statistically significant.

Table 1: Showing improvement of symptoms after treatment

\begin{tabular}{|l|l|l|l|l|l|}
\hline Group & $\begin{array}{l}\text { No. of patients } \\
\text { (M:F) }\end{array}$ & Mode of Treatment (duration) & \multicolumn{2}{|l|}{ Improvement in symptom } \\
\cline { 3 - 5 } & & $\begin{array}{l}\text { Burning } \\
\text { sensation }\end{array}$ & Ulceration & Mouth opening \\
\hline Group A & 40 & $\begin{array}{l}\text { Oral lycopene and vit. B complex } \\
\text { (4 months) }\end{array}$ & $62 \%$ & $70 \%$ & $0 \%$ Nil \\
\hline Group B & $40: 10)$ & $\begin{array}{l}\text { Intralesional injection of } \\
\text { Triamcinolone acetonide 40 mg. } \\
\text { with Hyaluro nidax 1500 IU } \\
\text { weeckly (8 inj) + oral lycopen } \\
\text { and Vit. B complex 4 months }\end{array}$ & $92 \%$ & $80 \%$ & $\begin{array}{l}80 \% \text { with sense } \\
\text { of Relaxation } \\
62 \% \text { increase } \\
\text { incisal }\end{array}$ \\
& $(35: 5)$ & $\begin{array}{l}\text { Inter } \\
\text { distance }\end{array}$ \\
\hline
\end{tabular}

Table 2: Showing increase in inter incisal distance in those patients given intralesional injections

\begin{tabular}{|l|l|l|}
\hline \multirow{2}{*}{ Increase in inter incisal distance } & NO. of Patients \\
\cline { 2 - 3 } & Group A & Group B \\
\hline No increase & 35 & 15 \\
\hline $1-5 \mathrm{~mm}$ & 5 & 4 \\
\hline $6-10 \mathrm{~mm}$ & 0 & 5 \\
\hline $11-15 \mathrm{~mm}$ & 0 & 16 \\
\hline $16-20 \mathrm{~mm}$ & 0 & 0 \\
\hline
\end{tabular}

\section{Discussion}

Oral sub-mucous fibrosis is a well-known clinical entity since the time of Shuhtura. It was Schwartz in 1962 who the first reported OSMF in modern literature and Joshi in 1953 described the entity in India $[4,5]$.

Chewing of arecanut is one of the most important factors responsible for OSMF. During the last two decades the chewing of arecanut has received a boost with the advent of pan masala $[3,6]$. Pan masala is available in small sachets, manufactured and commercially marketed in India. In our study of a series of 80 patients with OSMF, all patients gave a history of chewing gutkha, on an average 2-8 packet per day.

The patients presented with symptoms of hypersensitivity to spicy food, oral ulcers and feeling of stiffness in the mouth. The maximum cases belonged to the age group of 21 to 30 years. Similar results have been reported by Gupta PS et al.[2] in their epidemiological study of OSMF. They reported that prevalence is high in the lower age group i.e. between 15-25 years. Various other authors have reported the rise in OSMF in teenagers [7].

Among the systemic factors the main factors are chronic iron deficiency and deficiency of vitamin B complex. Martin and Koop considered Vitamin B deficiency to be important in the aetiology of degenerative changes in oral mucosa [8]. Kumar A et al in 2007 evaluated efficacy of oral lycopene in patients with OSMF and compared these effects with placebo. Patients receiving lycopene showed and average increase of $3.4 \mathrm{~mm}$ in mouth opening and patients receiving a combination of steroids and lycopene showed $4.6 \mathrm{~mm}$ increase, while patients receiving placebo showed no improvement. They suggested that lycopene should be the first line of treatment in OSMF [9]. In the present study patients only on oral vitamin B complex and 
lycopene showed improvement in burning sensation and oral ulceration but only 5 patients showed improvement in mouth opening of $1-5 \mathrm{~mm}$.

Kakar et al reported that patients treated with hyluronidase showed quicker improvement in symptoms but a combination of dexamethasone gave better and long term results [10]. Steroids are well known immunosuppressive agents for suppression of fibro productive inflammation found in OSMF. Hyaluronidase degrades the fibrous matrix promoting lysis of fibrinous coagulum and activating specific plasmatic mechanism.

Relief of symptoms of stiffness in oral cavity occurs through softening and diminishing fibrous tissue. In the present study intralesional triamcinolone injection with injection hyaluronidase was given once a week to make the treatment cost effective and for better patient compliance.

These patients showed relief of symptoms of burning sensation, hypersensitivity to spicy food and oral ulceration along with a subjective sense of decrease sense of stiffness in buccal mucosa after administration of 2 injections, though final results have been reported after a course of 4 months and 2 months follow up.

Similar results were reported by Lai DR \& Chen HR in their report of clinical evaluation of different treatment methods of OSMF in 150 cases [11]. Patients receiving biweekly submucosal injections of dexamethasone and hyaluronidase showed relaxation in stiffness of their buccal mucosa whereas no improvement of symptoms of trismus and blanching were seen in patients receiving oral vitamin B complex, peripheral vasodilator (buflomedial hydrochloride) and topical triamcinolone acetonide. In their study 75 patients received surgical treatment of excision of fibrous bands with graft placement.

They concluded that there is significant improvement in trismus at the end of the surgery, though a decline in inter incisal distance occurs by varying amount as grafts and wounds contract.

Borle and Borle did a comparative study of the effect of submucosal injectionof triamcinolone in one OSMF group and chewable Vit A, Ferrous fumarate, topical betamethasone in another group. Trismus was more pronounced in the second group after follow up [12]. In a series of cases studied by Khanna JN, Andararade NN in 1995, cases revealed improvement in clinical symptoms and mouth opening after triamcinolone injection while advanced stages treated surgically gave encouraging results in mouth opening [13].
The various other treatment modalities of treatment include intralesional injection of placental extracts. The action is essentially biogenic stimulation and used is based on tissue therapy method [14]

Surgical treatment includes excision of fibrous band with split thickness skin graft, fresh amnion graft, pedicle buccal pad graft [15-17]. Excision of fibrous band has also been undertaken by CO 2 and KTP laser [18, 19].

\section{Conclusion}

The role of vitamin supplement and lycopene is limited to relief of burning sensation and ulceration but provide no relief to trismus. Intralesional infiltration of triamcinolone with hyluronidase is effective in treating burning sensation and ulceration as well as trismus in OSMF. No side effects were seen in both the study groups. Awareness programme should be promoted in school and colleges about OSMF, seeing higher incidence in student population.

\section{Funding: Nil \\ Conflict of interest: Nil \\ Permission from IRB: Yes}

\section{References}

1. Cannif JP, Harvey W, Harris M. Oral submous fibrosis: its pathogenesis and management. $\mathrm{Br}$ Dent J.1986; 160(12):429- 34.

2. Gupta PC, Sinor PN, Bhonsle RB, Pawar VS, Metha HC. Oral submucous fibrosis in India. A new epidemic? Natl Med J India.1998 May-June; 11(3):113-6.

3. Ahmad MS, Ali SA, Ali AS, Chaubey KK. Epidemiological and etiological study of oral submucous fibrosis among gutkha chewers of Patna, Bihar, India .J Indian Soc Pedod Prev Den. 2006 June; 24(2): 84-9.

4. Pindborg JJ, Sirsat SM. Oral submucous fibrosis. Oral Surg Oral Med Oral Pathol.1966Dec; 22(6): 764-79.

5. Pindborg JJ, Metha FS, Daftary DK. Occurrence of epithelial atypia in 51 Indian villagers with oral submucous fibrosis. Br J Cancer1970 June; 24(2); 253-7.

6. Maher R, Lee AJ, Warnakulasuriya, KA, Lewis JA, Johnson NW. Role of areca nut in causation of oral submucous fibrosis: a case control study in Pakistan. J. Oral Pathol Med.1994 Feb; 23(2); 65-9.

7. Babu S, Sesikaran B, Bhat RV. Oral fibrosis among teenagers chewing tobacco, areca nut and pan masala.Lancet.1996 Sep 7;348(9028): 692. 
8. MartinH, Koop EC. Precancerous mouth lesions of avitaminosis $\mathrm{B}$ : their aetiology, response to therapy and relationship to intraoral cancer. Am J Surg. 1942; 57: 195.

9. Kumar A. Efficacy of lycopene in management of oral submucous fibrosis. Oral Surgery, Oral medicine, Oral Pathology, Oral Radiol Endod .2007;103:214-15.

10. Karkar PK, Puri RK,,Venkatachalam VP. Oral submucous fibrosis treatment with hyalase. J Laryngol Otol.1985 Jan; 99(1):57-9.

11. Lai DR, Chen HR, Lin LM, Huang YL, Tsai CC. Clinical evaluation of different treatment methods for oral submucous fibrosis. A 10-year experience with 150 cases. J Oral Pathol Med. 1995 Oct; 24(9):402-6.

12. Borle RM, Borle SR. Management of oral submous fibrosis: A conservative approach. J Oral Maxillofac Surg 1991Aug; 49(8); 788-91.

13. Khanna JN, Andrade NN. Oral submucous fibrosis: A new concept in surgical management. Report of 100 cases. J Oral Maxillofac Surg. 1995 Dec; 24(6):433-9.
14. Gupta D, Sharma SC. Oral submucous fibrosis - a new treatment regimen. J Oral Maxillofac Surg.1988 Oct; 46(10):830-3.

15. Samman N, Cheung LK, Tideman H. The buccal fat pad in oral reconstruction. Int $\mathrm{J}$ Oral Maxillofac Surg.1993Feb; 22(1):2- 6 .

16. Tideman H, Bosanquet A, Scott J. Use of the buccal fat pad as a pedicled graft. J Oral Maxillofac Surg. 1986 Jun; 44(6):435- 40.

17. Dino BR, Eufemio GG, De Villa MS. Human amnion; the establishment of an amnion bank and its practical applications in surgery. J Philipp Med Assoc.1965Jul; 42(7):357-66.

18. Frame JW. Carbon dioxide laser surgery for benign oral lesions. Br Dent J.1985 Feb; 158(4):125-8.

19. Strong MS, Jako GJ, Polanyi T, Wallace RA. Laser surgery in the aerodigestive tract. Am J Surg.1973 Oct; 126(4):529-33.

\section{How to cite this article?}

Goswami R, Gangwani A, Bhatnagar S, Singh D. Comparative study of Oral Nutritional Supplements vs Intralesional Triamcinolone and Hyaluronidase in Oral Submucous Fibrosis. Int J Med Res Rev 2014;2(2):114-118. doi:10.17511/ijmrr.2014.i02.08. 